\title{
AN ASSESSMENT OF FACTORS INFLUENCING EMPOWERMENT LEVEL OF FEMALES: A CASE STUDY OF POKHARA
}

\author{
Arjun Kumar Thapa* Leena Gurung ${ }^{* *}$
}

\begin{abstract}
This study is an attempt to analyze the association between social, economic and demographic factors on the female teachers' empowerment level. A cross-sectional data was generated following two stage random sampling. First 20 schools were selected then 189 respondents were randomly selected and interviewed. In this study rather than women's age, age at marriage, work experience and husband's education and occupation, women's self achievement to earn more income, economic status and positive attitude towards job have positive influence in enhancing empowerment. This study underpins the importance of economic interventions to empower and uplift all round condition of women. Along with it this paper again stirs the most heated debate among the activist, academicians and service providers regarding appropriate intervention strategy for upliftment of women.
\end{abstract}

Key words: empowerment, women, economic, social and demographic factors, Pokhara

\section{BACKGROUND}

All the development efforts would be only half done if there is no effective participation of females. Empowerment emerged as an important theme in the women's movement from 1975 onwards. In fact, empowerment as a theme arose out of a failure of 'Women in Development' (WID) programs, notably the equity approach all of which failed to question the interrelationship between power and development. Kabeer (2001) argues that Empowerment is the processes by which women take control and ownership of their lives through expansion of their choices. Thus, it is the process of acquiring the ability to make strategic life choices in a context where this ability has previously been denied. Nepal Human Development Report 2004 captures the spirit of human development which is defined as "creating an environment, in which people can develop their full potential and lend productive, creative lives in accord with their needs and interests to be able to participate in the life of the community (UNDP, 2004). Bennett (2002) has developed a framework in which "empowerment" and "social inclusion" are closely related. Bennett describes empowerment as "the enhancement of assets and capabilities of diverse individuals and groups to engage, influence and hold accountable the institutions which affect them."

* Mr. Thapa is Lecturer of Economics School of Development and Social Engineering, Pokhara University, Lekhnath Marga Email: giriarjun2003@yahoo.com

** Ms. Gurung is Vice Chairperson Kopila Nepal, Dighapatan Pokhara Email: leena.gurung@yahoo.in 
A study carried out by Shrestha (1995) to understand the levels and patterns of literate and educated females' economic participation in Nepal especially in Kathmandu found level of education attained and participation in economic activities has positive association in facilitating empowerment of women. But a study carried out by Koirala, (2006) in Sarankot VDC found that the factors like age, caste, occupation, education, family size and husband's occupation do not significantly influence influencing economic and social empowerment of women involved in microfinance program. Sharma (2004) from her research study, entitled 'Empowerment process of community women' concluded that women's empowerment process is highly determined by community setting, culture, family size, age of marriage of women, no of children, mobility and extra time for new creative activities. Still not much empirical study been carried out. What factors actually determine empowerment of women has mixed versions.

\section{OBJECTIVE AND METHODOLOGY}

The objective of this paper is to analyze the association of women's age, age at marriage, income, qualification, economic status, work experience, attitude towards job and husband's education and occupation on the level of empowerment. The respondent for the study were currently married ever pregnant female teachers teaching at primary level in private schools of Pokhara Sub-metropolitan (PSMM). First a list of all the private schools was obtained from the District Education Office, Kaski and 20 schools were sampled randomly, 20\% from a list of 129 registered private schools in Pokhara municipality. Then a pre-test of the questionnaire was administered for the reliability and validity in three private schools. Then 189 female married teachers were selected for the purpose of study through probability proportion to size. Questionnaire schedule was applied to gather important and essential information in this research study. In the process, teachers involved in the profession for many years were brought together for focus group discussion (FGD). The main sources of secondary data and information were collected from Nepal Human Development Report 2004, Central Library of Pokhara University, Central Library of Tribhuvan University, Regional Library of PrithviNarayan Campus and District education office, Kaski.

\section{Model and Construction of Empowerment Level}

Various scholars and organizations have developed their own method of measuring empowerment level. The indicators in this research study for computing empowerment index are influenced mainly from the human empowerment index of UN model given in Nepal Human Development Report, 2004 and Malhotra's (2002) commonly used dimensions of empowerment and potential operationalization in the household, 
community, and broader arenas. Level of empowerment is dependent variable and various socio-economic and demographic factors are independent variables. The dependent variable, empowerment score $(\mathrm{Y})$ was computed by giving scores and creating Likert in about 50 questions of concern. Then index for this study was categorized into two levels: low empowerment level and high empowerment level ranging from below and above the average.

A linear regression model was run as:

$Y=a+b_{1} X_{1}+b_{2} X_{2}+b_{3} X_{3}+b_{4} X_{4}+b_{5} X_{5}+b_{6} X_{6}+b_{7} X_{7}+b_{8} X_{8}+b_{9} X_{9}+b_{10} X_{10}+U$

where,$Y=$ empowerment level, $X_{1}=$ Age,$X_{2}=$ Race, $X_{3}=$ qualification, $X_{4}=$ age at marriage, $X_{5}=$ salary/income,$X_{6}=$ working experience, $X_{7}=$ husband's occupation, $X_{8}$ $=$ husband's education, $\mathrm{X}_{9}=$ family's economic status, $\mathrm{X}_{10}=$ perception towards job, $\mathrm{U}$ $=$ error term, $\mathrm{a}=$ intercept and $\mathrm{b}_{\mathrm{i}}$ s are parameters to be estimated.

The indicator of social, economic and political empowerment was changed into ratio scale from ordinal scale of data to identify the level of overall empowerment. The values were divided into two categories as high level of empowerment above the average mean and low empowerment level which is below the average mean. The result from the index may not be generalized in other settings. The model applied in this study has been influenced from UN Model of human empowerment index. (See annex-1)

\section{DATA PRESENTATION AND ANALYSIS}

The data are analysed under two headings: general profiles of the respondents and regression analysis.

\section{Analysis of General Profile of the Respondents}

The information on the general profiles of the respondents is summarized in Table 1. Obviously the information contained in Table 1 indicates that women above 30 years are more empowered (58.9 \%) than women of 30 or below 30 years. It is as per the established tendency that as the age of the women increases the empowerment level also increases. Regarding the caste, Indo-Aryan women are more likely to be empowered than Tibeto-Burman women in Nepalese society. 
Table 1: Percentage Distribution of Respondents by level of empowerment and socio-economic factors, work experience and family background

\begin{tabular}{|c|c|c|c|c|c|c|c|}
\hline \multirow{3}{*}{ Variable } & \multirow{3}{*}{ Category } & \multicolumn{4}{|c|}{ Empowerment } & \multirow{2}{*}{\multicolumn{2}{|c|}{ Total }} \\
\hline & & \multicolumn{2}{|c|}{ Low } & \multicolumn{2}{|c|}{ High } & & \\
\hline & & $\mathrm{N}$ & $\%$ & $\mathrm{~N}$ & $\%$ & $\mathrm{~N}$ & $\%$ \\
\hline \multirow{2}{*}{$\underset{\infty}{\infty}$} & Below 30 & 49 & 49.5 & 50 & 50.5 & 99 & 52.4 \\
\hline & Above 30 & 37 & 41.1 & 53 & 58.9 & 90 & 47.6 \\
\hline \multirow{2}{*}{ 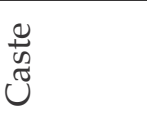 } & Indo-Aryan & 40 & 42.1 & 55 & 57.9 & 95 & 50.3 \\
\hline & Tibeto-Burman & 46 & 48.9 & 48 & 51.1 & 94 & 49.7 \\
\hline \multirow{3}{*}{ 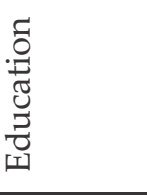 } & School Leaving Certificate & 23 & 48.9 & 24 & 51.1 & 47 & 24.9 \\
\hline & Intermediate & 39 & 55.7 & 31 & 44.3 & 70 & 37.0 \\
\hline & Bachelor or above & 24 & 33.3 & 48 & 66.7 & 72 & 38.1 \\
\hline \multirow{2}{*}{ 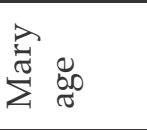 } & 20 and below 20 years & 40 & 47.1 & 45 & 52.9 & 85 & 45.0 \\
\hline & Above 20 years & 46 & 44.2 & 58 & 55.8 & 104 & 55.0 \\
\hline \multirow{2}{*}{ 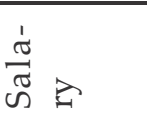 } & Below Rs 5,000/- & 36 & 70.6 & 15 & 29.4 & 51 & 27.0 \\
\hline & Above Rs 5,000/- & 50 & 36.2 & 88 & 63.8 & 138 & 73.0 \\
\hline \multirow{3}{*}{ 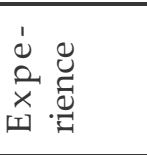 } & 5 or below 5 years & 34 & 56.7 & 26 & 43.3 & 60 & 31.7 \\
\hline & $5-10$ years & 33 & 50 & 33 & 50 & 66 & 34.9 \\
\hline & Above 10 years & 19 & 30.2 & 44 & 69.8 & 63 & 33.3 \\
\hline \multirow{4}{*}{ 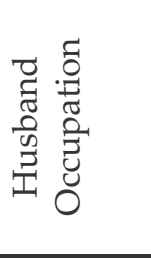 } & Self-employed & 22 & 50 & 22 & 50 & 44 & 23.3 \\
\hline & Govt. Employee & 41 & 34.3 & 79 & 65.7 & 120 & 63.5 \\
\hline & $\begin{array}{l}\text { INGO/NGO/Private } \\
\text { companies }\end{array}$ & 33 & 47.8 & 36 & 52.2 & 69 & 36.5 \\
\hline & Abroad & 19 & 46.3 & 22 & 53.7 & 41 & 21.7 \\
\hline \multirow{2}{*}{ 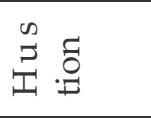 } & Intermediate and below & 36 & 52.9 & 32 & 47.1 & 68 & 36.0 \\
\hline & Bachelor and above & 50 & 41.3 & 71 & 58.7 & 121 & 64.0 \\
\hline \multirow{3}{*}{ 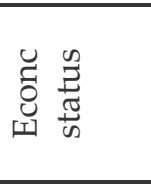 } & Low & 33 & 66 & 17 & 34 & 50 & 26.5 \\
\hline & Medium & 41 & 39.4 & 63 & 60.6 & 104 & 55.0 \\
\hline & High & 12 & 34.3 & 23 & 65.7 & 35 & 18.5 \\
\hline \multirow{2}{*}{ 응 } & Lowly positive & 32 & 58.2 & 23 & 41.8 & 55 & 29.1 \\
\hline & Highly positive & 54 & 40.3 & 80 & 59.7 & 134 & 70.9 \\
\hline
\end{tabular}

Source: Authors Computation. 
Indo-Aryan consist of Brahmin, Chhetri and dalit women while Tibeto-Burman consist of Gurung, Thakali, Magar, Rai, Tamang, Newar etc. As dalit female teachers were of very few in numbers, it has been incorporated in the first category of IndoAryan. Further the table shows that there is direct relationship of qualification with empowerment level of teachers. Females who have passed School Leaving Certificate, Intermediate level and Bachelor level or above have empowerment level of $51.1 \%, 44.3$ $\%$ and $66.7 \%$ respectively. Majority of women (55.8\%) who got married above 20 years of age were found comparatively with high level of empowerment than with them who got married at the age of 20 or below 20 years which is only 52.9 percent. The table reveals that higher the salary higher is the level of empowerment.

Economic factors seemed to be an important contributing factor for increase in empowerment level. Similarly work experience is also significantly associated with the empowerment of female teachers.

As women gain experience in teaching profession, there is increment in empowerment level. Teachers who have worked in schools for more than 10 years have the highest $(69.8 \%)$ level of empowerment while who have worked between 5 to 10 years and below 5 years occupy 50 and 43.3 percent respectively. Regarding the association of husband's occupation with the empowerment level, it was found that female teachers whose husband work as government employee are highly empowered (65.7\%) comparatively to women with husband working abroad (53.7\%), INGO/NGO/Private companies (52.2\%) and who are self employed (50\%).

The females whose husband's education level was higher seemed to be more empowered compared to those whose husbands were having lower qualification. The economic status of the family which includes the annual income of the family, property owned and gadgets utilized for life style which was categorized into low, medium and high. Those women who come from family having high economic status were highly empowerment than others. When employees have highly positive attitude/perception towards their job, they are likely to more empower. As shown in the table about 60 percent of female teachers who have highly positive attitude toward their job are found to be more empowered.

\section{Linear Regression Analysis}

To investigate the directional and magnitude impact of socio-economic and demographic factors on the level of empowerment a linear regression was run. The results of the multiple regression analysis obtained are given in Table 2.The predictors are: constant, age of the respondent, age at marriage, work experience, caste, qualification, current salary, husband's education level, husband's occupation, economic status of the family.

In the table the variables which have asterisk sign $\left(^{*}\right)$ are the statistically significant variables. Thus races, current salary, economic status of family and job perception are significantly affecting female empowerment. In reference to Indo-Aryan Race Tibeto- 
Burman female teachers are negatively significant. It means Tibeto-Burman female teachers are low empowered in comparison to Indo-Aryan female teachers. IndoAryan are the Aryan race where castes like Brahmin, Chhetri and Dalits are included and other type of caste mainly Janjatis like Gurung, Magar, Thakali, Newar, Rai, come under Tibeto-Burman who belong to Mongolian race. From the above mentioned result inference can be drawn that Aryan race particularly Brahmin and Chhetri are more empowered than Janjatis of Nepal.

Table 2: Determinants of Empowerment: Regression Results

\begin{tabular}{|c|c|c|c|}
\hline Model & $\mathrm{R}$ & Adjusted R Square & Std. Error of the Estimate \\
\hline 1 & $.499(\mathrm{a})$ & .209 & 5.637 \\
\hline
\end{tabular}

\begin{tabular}{|c|c|c|c|c|}
\hline \multirow{2}{*}{ Predicator Variables } & \multicolumn{2}{|c|}{ Standardized Coefficients } & \multirow[t]{2}{*}{ t values } & \multirow[t]{2}{*}{ P Value } \\
\hline & Beta (B) & Std. Error & & \\
\hline Constant & 17.454 & 4.968 & 3.513 & 0.699139 \\
\hline Age of the respondent & 0.24 & .120 & .198 & 0.420889 \\
\hline Age at marriage & -.071 & .154 & -.464 & 0.886198 \\
\hline Work Experience & .216 & .118 & 1.828 & 0.913163 \\
\hline Race : $* * *$ & & & & ? \\
\hline Indo-Aryan (ref) & & & & 0.000393 \\
\hline Tibeto-Burman & -1.738 & .942 & -1.845 & \\
\hline Qualification : & & & & 0602722 \\
\hline S.L.C (ref) & & & & \\
\hline Intermediate & -.164 & 1.168 & -.140 & \\
\hline Bachelor or above & 2.037 & 1.261 & 1.616 & \\
\hline Current Salary $* *$ & 2.443 & 1.074 & 2.275 & 0.02422 \\
\hline $\begin{array}{l}\text { Husband's education : } \\
\text { S.L.C (ref) }\end{array}$ & & & & \\
\hline Intermediate level & -1.709 & 1.239 & -1.380 & \\
\hline Bachelor level & .050 & .961 & 0.52 & \\
\hline $\begin{array}{l}\text { Husband's occupation : } \\
\text { self employed ref) }\end{array}$ & & & & 0.2788 \\
\hline Government employee & 2.043 & 1.338 & 1.527 & \\
\hline $\begin{array}{l}\text { NGO/NGO/Private } \\
\text { Companies }\end{array}$ & 1.050 & 1.122 & .936 & \\
\hline Abroad & 1.754 & 1.279 & 1.371 & \\
\hline Family Economic Status* & .822 & .720 & 1.143 & 0.0877 \\
\hline Job Perception * & 1.223 & .464 & 2.635 & 0.0622 \\
\hline
\end{tabular}

* Significant at 99 percent level of significance, ${ }^{* *}$ significant at 95 percent level of significance, ${ }^{*}$ significant at 90 percent level of significance

With reference to Aryan race Mongolians are less likely to be empowered by 1.7 times. 6 
Current salary is highly significant in empowering females. For a unit point increase in salary the empowerment level of females increases by 2.4 times. Similarly attitudes towards job are also positively significant. Except race, other variables like perception, economic status and salary is found to have positive and significant impact whereas race is explored to be negatively associated with the empowerment level of female teachers.

It is found that these predicators can explain 21 percent of variance (Adjusted $R^{2}$ ) in the dependent variable (empowerment level of females). It may be due to other intervening variables coupled with the qualitative nature of most of the predictors.

\section{CONCLUSION}

From the study, we can conclude that rather than women's age, age at marriage, work experience and husband's education and occupation, women's self achievement to earn more income, qualification, economic status, work experience and positive attitude towards job is more responsible in the process of empowerment. Furthermore, positive perception, high salary and good economic status are explored to be the most contributing factor for empowering the female teachers. Therefore economic intervention is most important way to empower women as it will bring change in economic status of her family and remove her dependency upon the family.

The role of an agent of change will not only make her to play the role of a bread winner and decision maker but would also create such an environment to take other women along with her to the path of empowerment. Henceforth for the sustainable development of the country, government has to promote the role of women in every social, political and economic activities of the development equally to male counterparts through the effective implementation of its gender friendly policies, strategies and programmes.

\section{References}

Acharya, M. (1997). Gender Equality and Empowerment of Women, Status Report. Kathmandu: UNFPA.

Bhasin, K. (2004). Understanding Gender. New Delhi: Women Unlimited.

District Education Office (2063). Kaski Shaichik Dharpan, Kaski: District Education Office.

Devkota, M. (2007). Educated Women in Government Employment, Unpublished Dissertation, submitted to the department of Sociology/Anthropology, Pokhara: Prithvi Narayan Campus.

Kabeer, N, (2001). Resources, Agency, Achievements Reflections on the Measurement of Women's Empowerment, in Discussing Women's Empowerment - Theories and Practice. SIDA Studies No.3. Stockholm: Novum Grafiska AB. 
Koirala, R. (2006). Micro Finance and Women Empowerment in Sarangkot VDC, Unpublished dissertation, submitted to Faculty of Humanities and Social Science, Lekhnath Municipality: Pokhara University.

Lamichhane, J (2008). Determinants of Maternal Health Service Utilization in Nepal, Unpublished dissertation, submitted to the Faculty of Humanities and Social Sciences, Lekhnath Municipality: Pokhara University.

Malhotra, A. (2002). Conceptualizing and Measuring Women's empowerment as a variable in international development, Washington DC: International Center for Research on Women.

Sharma, C. (2004). Empowerment Process of Community Women, Unpublished Dissertation, submitted to the Department of Sociology/Anthropology, Tribhuvan University, Lalitpur: Patan Multiple Campus.

Shrestha, P. (1995). Educated Women in Urban Nepal, Delhi - 110052: B.R. Publishing Corporation.

United Nations Development Programme (2004). Nepal Human Development Report 2004: Empowerment and Poverty Reduction, Kathmandu: UNDP.

ANNEX - I

Social empowerment index (SEI) $=$ LE+DRH+SRDM+ICGW

Where,

LE $\quad$ Level of Education

$\mathrm{DRH}=$ Decision in Reproductive Health; SRDM = Sharing Roles in Domestic

Matter; ICGW = Involve in Community Group Work

Economic Empowerment Index $(\mathrm{EEI})=\mathrm{ACC}+\mathrm{MHB}+\mathrm{EWD}+\mathrm{AIC}$

Where,

ACC = Access to and Control of Cash; MHB=Management of Household

Budget; $\mathrm{EWD}=$ Equal Wage Distribution; $\mathrm{AIC}=$ Access to Institutional Credit

Political Empowerment Index $(\mathrm{PEI})=\mathrm{VE}+\mathrm{PPC}+\mathrm{ABLR}+\mathrm{PA}$

Where,

$\mathrm{VE}=$ Vote in Election; $\mathrm{PPC}=$ Participation in Political Campaigns $; \mathrm{ALR}=$

Awareness of Basic Legal Rights; $\quad$ PA = Political Affiliation

Overall Empowerment Index $=(\mathrm{SEI}+\mathrm{EEI}+\mathrm{PEI}) / 3$ 